\title{
Diplopia and Torticollis in Adult Strabismus
}

\author{
Dora D Fdez-Agrafojo ${ }^{1 *}$, Hari Morales ${ }^{2}$ and Marta Soler ${ }^{2}$ \\ ${ }^{1}$ Doctor in medicine and surgery, Teknon Medical Center, Spain \\ ${ }^{2}$ Optometrist, Teknon Medical Center, Spain
}

Submission: November 11, 2016; Published: January 16, 2017

*Corresponding author: Dora D Fdez-Agrafojo, INOF Center, Teknon Medical Center, Barcelona, Spain, Tel: 933933156;

Email: fdezagrafojo@dr.teknon.es

\section{Abstract}

Objective: To expose the diagnosis of an adult patient with vertical and unilateral divergent strabismus and to approach the surgical treatment in order to remove the symptoms of diplopia and signs of torticollis.

Method: The measurement of the angle of deviation, the Lancaster test, the Bielchowsky test and the study of ocular motility, both in examination room (versions) and in the surgery room (test of ductions), demonstrated the diagnosis: right eye hipertropia (HTR) and right eye exotropia (XTR). Surgical intervention was performed on the right upper rectus muscle and on the right inferior oblique muscle, with the aim of resolving the deviation of both directions in only one surgical intervention.

Results: The intervention was satisfactory for both the patient and the medical team, because we were minimized the signs and symptoms. After 4 months the residual deviation angle was minimal and allowed the ability of fusion.

Conclusion: The diagnostic and treatment protocol performed in this case show the optimal resolution of the diplopia and torticollis that the patient suffered.

Keywords: Strabismus; Torticollis; Diplopia; Lancaster test

\section{Introduction}

We believe that, in some cases, in strabismus surgery there may be more than one option in the choice of surgical protocol, and each professional and his experience sets a more personalized pattern of action. Our objective is showing through this case, for ophthalmologists and other professionals who visit adult patients with strabismus, our experience in the surgical treatment of vertical and divergent deviation with torticollis and an associated diplopia [1-5].

\section{History, Data and Method of Diagnostic Exploration}

Patient 41 years old. The patient refers diplopia in increase for a year and torticollis for years. Tilt the head to the left shoulder to try to compensate the diplopia. Ocular antecedents: Lasik refractive surgery (myopia -5.00 both eyes).

\section{Family history: Glaucoma.}

\section{Pre-surgery exploration}

a. Visual acuity without correction right eye $=1$

b. Visual acuity without correction left eye $=1$ c. Refraction (cycloplegic) right eye $=+1.50-0.50 \times 170^{\circ}$

d. Refraction (cycloplegic) left eye $=+0.50-0.75 \times 145^{\circ}$

e. Corneal topography: Central ablation in both eyes.

f. Normal ophthalmic examination.

g. Synoptophore without correction in superaversion = $22 \Delta$ XTR / $28 \Delta$ HTR. Primary position of gaze $=17 \Delta$ XTR / $28 \Delta$ HTR. In Infraversion $=9 \Delta$ XTR $/ 30 \Delta$ HTR.

h. Left eye dominance

i. Stereopsis test (Titmus / Fly): There is no stereopsis.

\section{Method Surgical}

The day of the surgery is performed a tests of duction: right upper oblique muscle (- -)

\section{Surgical protocol}

Backward movement of right upper rectus muscle $3 \mathrm{~mm}$. Backward movement of right inferior oblique muscle $6 \mathrm{~mm}$. 


\section{Post-surgery exploration}

The synoptophore after the intervention in the primary position was $3 \Delta$ HTR. There is no existence of stereopsis, but it can even fusion the images. The patient is subjectively satisfied. It is proposed, 4 months after the surgery, to begin orthoptic treatment to strengthen the ability of fusion images [5-10].

\section{Discussion}

The deviation of an adult's strabismus is diagnosed and resolved the vertical and divergent strabismus in only one surgical intervention. It was discarded the differential diagnosis of nonocular torticollis by the examination tests. It was considered, for the good maintenance of the obtained result and maintenance of the ability of fusion, to perform an orthoptic treatment after surgery. We consider that the patient will have more visual quality in their daily life when resolving their symptoms of diplopia, signs of torticollis and ocular asymmetry. We emphasize the exploration by the Lancaster test in patients with diplopia for its ease of use, graphical representation and its diagnostic ability and the following of the case over time.

\section{Conclusion}

The diagnostic and treatment protocol performed in this case show the optimal resolution of the diplopia and torticollis that the patient suffered.

\section{References}

1. Benítez del Castillo (1996) JM Estrabología Práctica.

2. Burian HM, Von Noorden GK (1980) Binocular vision and ocular motility. Theory and management of strabismus $2^{\text {th }}$ (edn), CV Mosby, St. Louis, USA.

3. Ferrer Ruiz J (1991) Estrabismos y ambliopías. Práctica razonada. Ediciones Doyma, Spain.

4. Flynn, MD Mc Kenney S, Rosenhouse M (1975) Management of Intermitent Exotropia orthopties past, present, future transactions of third International Orthoptic Congress Boston, p. 1-3.

5. Galán Terraza A, Visa Nasarre J (2005) Diplopía Manual práctico con vídeos demostrativos. In: Glosa (Ed.), Barcelona, Spain.

6. Inatomi A (1957) Observations on the visual functions in strabismus. Report II. Observations on retinal suppression and correspondence. Acta So. Ophthal Jap 61(2): pp. 1529-1543.

7. Jeanrot N, Jeanrot F (1996) Manual de estrabología práctica. Aspectos clínicos y terapéuticos. MASSON, Spain.

8. Lang (1981) Strabisme Diagnostic. Formes cliniques traitement. In: Hans Huber (Ed.), Berne, Spain, p.65.

9. Prieto Diaz J y Souza Dias C Estrabismo. In: Julio, jims (Eds.).

10.Zamora M (1988) Iniciación a la Estrabología. In: Sharp M, Dohme (Eds.), Madrid, Spain.

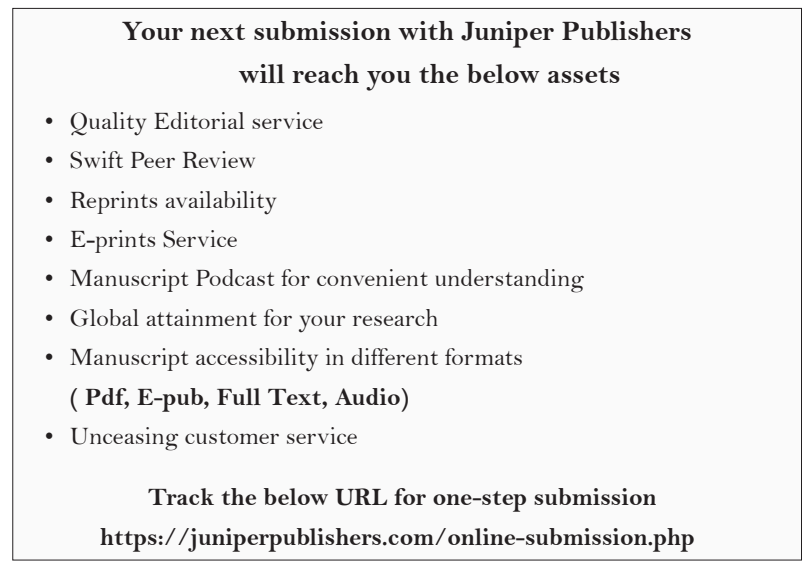

